\title{
Design of Text Comprehension Activities with RETUDISAuth
}

\author{
Grammatiki Tsaganou and Maria Grigoriadou \\ University of Athens, Dept. of Informatics \& Telecommunications
}

Greece

\section{Introduction}

The cognitive psychological approach in text comprehension suggests that the internal variables of the reader hold a primary role in text comprehension, such as his personal goals, interests and pre-existing knowledge. However, cognitive science does not ignore the influence of the text form, in which factors such as text cohesion and logical coherence of facts presented have been proved to be significant elements that facilitate its comprehension (DeCorte et al., 1982). Recent discussions, directions and research results on text comprehension concern the structural analysis of science texts and cognitive aspects of text elements, such as causal relationships between text elements. Different studies on text comprehension have focused their interest on the sentence structure presented by the text (Brown \& Day, 1983; Kintsch, 1998). Sentence structure of a text could be organized on the basis of hierarchy in order to allow the importance of sentences in the text to be revealed (Van Dijk, \& Kintsch, 1983). In approaching text comprehension, researchers examine issues that focus on assisting comprehension through text summarization (Brown \& Day, 1983) by improving text coherence (McNamara, 1996; Kintsch, 1998; Graesser \& Tipping, 1999) or assisting the design of the text form and text activities (Baudet \& Denhière, 1992).

Text comprehension theory of Baudet \& Denhière, supports that readers build mental representations of information contained in the text during the comprehension process. Primary role should be attributed to the understanding of cognitive categories such as entity, state, event and action as well as temporal and causal relationships connecting these structures (Leon \& Penalba, 2002). This consideration deals with text comprehension as the attribution of meanings to causal and temporal connections between occurrences in the text. Furthermore, the organization and structure of cognitive representation should involve three system types: relational system, transformational system and teleological system and should be examined on micro and macro-levels (Baudet \& Denhière, 1992). The design of the structure of text activities is important in order to enhance learning in an educational system.

In order to make the information in such activities available to target users (students, teachers, researchers, authors, educators) new efforts have emerged to bring together novel methodologies and technologies. Authoring such activities demands an authoring system which involves knowledge acquisition, design process and managing a large amount of complex information. Authoring tools offer the appropriate structure and guide authors to 
import and elaborate educational material (text, questions, dialogues etc.). Researchers have been investigated Intelligent Tutoring Systems (ITS) with authoring tools almost since the beginning of ITS research and authoring systems have been built (Koedinger \& Anderson, 1995; Schultz et al., 2003). An authoring tool is a generalized framework along with a user interface that allows non programmers to formalize their knowledge (Koedinger \& Anderson, 1995; Ritter \& Blessing, 1998; Wong \& Chan, 1997). Part of authoring an ITS is the systematic decomposition of the subject matter into a set of related text elements. Each authoring system provides tools or cues which assist the author in this process of breaking down and elaborating the content to the necessary level of detail according to an instructional model. There are intelligent adaptive hypermedia systems like CALAT (Muray, 2003) and GETMAS (Wong \& Chan, 1997) that their functions overlap those from both the above categories. There are also expert systems, like Dempndtr8 (Blessing, 2003), IRIS-tutor (Arruarte et al., 2003) which include rule-based cognitive models of problem solving expertise and observe learner behaviour in order to build a learner model.

In this chapter we outline the process of structuring technical text educational material with questions and dialogue activities for text comprehension in the educational environment of ReTuDiS (Reflective Tutorial Dialogue System), using its' authoring tool, ReTuDiSAuth. The technical text presented as an example concerns "Local Network Operation". Authors are guided to organize and structure text and activities involving the relational, transformational and teleological system and make descriptions on micro and macro-levels. The system supports text comprehension using questions and dialogue activities, adapted to different learner profiles. In this work we also report on evaluation results of the use of ReTuDiSAuth as an authoring tool.

\section{Text Comprehension Theory}

In order to examine the representation constructed by learners during the comprehension process of a text, primary role should be attributed to the understanding of the cognitive categories entity, state, event and action (Baudet \& Denhière, 1992). The term entity refers to the atoms, units or persons participating in the representation structure. The term state describes a situation in which no change occurs in the course of time. The term event refers to an effect, which causes changes but is not provoked by human intervention. The event can be coincidental or provoked by human intervention, e.g. by a machine. An action causes changes but is originating by a man but is originating by a human intervention. Text comprehension is considered as the attribution of meaning to causal connections between occurrences in the text. Learners compose a representation of the text, which contains the cognitive categories: entity, state, event and action. For the interpretation of learners' cognitive processes their discourse is analysed, in order to trace the recognition (or not) of the cognitive categories.

Furthermore, text analysis in relation to the cognitive categories does not suffice (Baudet \& Denhière, 1992). The organization and structure of cognitive representation should involve three system types: relational system, transformational system and teleological system.

- The relational system represents a state in which there are entities of the possible world and no change occurs in the course of time, whereas part to whole relations define a hierarchy in the structure of the system.

- The transformational system represents complex events of the world or events' sequences which provoke transformation of static states. When a transformational 
system is causal then it is described as a causal path between events. When it is temporal the changes are temporal. Part to whole relations between events and macroevents define a hierarchy in the system.

- The teleological system is organized in a tree of goals and sub-goals and within a time period its' initial state, defined by the present entities, their relations and the values of their properties, changes turning into a final state performing in that way the predefined goal.

The organization and structure of cognitive representation should also be examined on micro and macro-levels. Mental representations capture elements of the surface text, of the referential meaning of the text, and of the interpretation of the referential meaning, thus constructing a micro-world of characters, objects, spatial settings, actions, events, feelings etc. The person who reads a text gradually constructs the microstructure of the text representation, i.e. the states, event and compound actions of the world described in the text as well as the time and causal relationships that interlock those structures.

On a micro-level scale, in order a person, to be able to explain the operation of a technical system, has to construct a representation of the "natural flow of things", where every new event should be causally explained by the conditions of events which have already occurred. The creation of a text that allows a precise description of a technical system and facilitates readers in constructing its microstructure representation must involve: (a) the description of the units that constitute the system based on the causal relationship which unites them and (b) the description of event sequence taking place in these units in respect of the cause affecting them as well as of the changes they bring to the state of the system.

On macro-level, the development of the macrostructure by readers is achieved through the reconstruction of the microstructure and the establishment of a hierarchical structure with goals and sub-goals. The creation of a text which facilitates readers in constructing its macrostructure representation for a system must involve the teleological hierarchical structure of goals and sub-goals of the various operations as well as their implications.

\section{Authoring Tools}

ITS authoring is both a design process and a process of knowledge articulation. While authoring tools are becoming more common and proving to be increasingly effective they are difficult and expensive to build. Authoring tools use methods to achieve the following goals (Ainsworth et al., 2003) a) decrease the effort of authoring (time and cost), b) allow others to take part in the design process $\mathrm{c}$ ) help the author articulate or organize his domain knowledge d) support good design principles concerning the pedagogy and the interface and e) allow quick evaluation cycles.

Authoring tools achieve the above goals using various of methods. Authoring systems use methods to simplify and automate authoring and knowledge acquisition. Part of authoring an ITS is the systematic decomposition of the subject matter into a set of related elements, for example a hierarchy. Each authoring system provides tools or cues which assist the author in this process of breaking down and elaborating the content to the necessary level of detail according to an instructional model.

Authoring tools allow non-programmers to build tutors by incorporating a particular model or framework to scaffold the task (Muray, 2003). Learner modelling process requires making certain choices, and it is in these choices that the learning process is located (Kay, 2001). We do not learn much from looking at a model, we learn from models by building them and 
using them (Jonassen, 2004; Morgan, 1999). Learning from building models involves finding out what elements fit together in order to represent the world of the model. The design of dialogue activities for adaptive learning supported by appropriate authoring tools attracts the interest of many researchers and educators in inventing new methodologies for effective teaching and learning. The authoring process activates authors to decompose the subject matter into a set of related elements to discover what elements fit together in order to represent a concept, for example a hierarchy. The authoring process, as a process of choosing, organizing, structuring and linking educational material becomes a process of learning.

Authoring tools for text comprehension have to discover and offer mechanisms which help authors design activities for the diagnosis of learners' difficulties in comprehending texts. They offer the appropriate structure and guidance in order the author to be able to import and elaborate educational material (text, questions, dialogues etc.). There has been a growing concern about scientific text comprehension (Brown \& Day, 1983). Efficient teaching and learning requires that educators should be familiar with the difficulties which learners are likely to face.

\subsection{ReTuDiS System}

ReTuDiS is a diagnosis and open learner modelling tutorial dialogue system for text comprehension. The system infers learners' cognitive profile in order to construct and revise the learner model with the learners' participation (Tsaganou et al., 2004). ReTuDiS consists of two parts: the Diagnosis part and the Dialogue part.

The diagnosis part of ReTuDiS approaches learner's text comprehension supporting the theory of Baudet \& Denhière that learner's representation of the text contains the cognitive categories: event, state and action (Baudet \& Denhière, 1992). The system engages learners in an activity which includes reading comprehension of text and answering question-pairs by selecting between given alternative answers. Learners' answers are used for diagnosing learners' text comprehension. Learners have to study all the text to comprehend it and select answers from the given alternative answers, in order to express their position on certain issues and support it by a justification. The diagnosis part infers learners' cognitive profile and his learner model.

The underlying theory beyond the dialogue part of ReTuDiS is the Theory of Inquiry Teaching (Collins, 1987). ReTuDiS approaches dialogue activities based on theories of dialogue management, strategies, tactics and plans which promote reflection in learning. The dialogue part is based on the learners' cognitive profile, inferred by the diagnosis part, the learners' answers to question-pairs and the selected dialogue strategy offered by the system. The dialogue part of ReTuDiS engages the learner in personalized reflective dialogues in order to revise the learner model with the participation of the learner (Tsaganou et al., 2004). The dialogue generator activates the appropriate for the learner sequence of dialogue-parts, and using the dialogue plan, dynamically constructs the individualized learning dialogue.

\subsection{ReTuDiSAuth}

ReTuDiSAuth, the authoring tool of system ReTuDiS, offers an environment that lays out the appropriate parameters an author needs to define. The authoring tool supports users registered as teachers or administrators. Teachers have the authority to create new activities 
or edit existing ones. Administrators of the system have the authority to manage the base of the users of the ReTuDiS and the educational material. The environment offers the tools and the shell (Figure 1). The tools, which add interactivity to the system and support authors to import educational material, are the following:

Text fields. These fields are designed to help authors enhance their own educational material into the system for example, titles of activities, texts, questions.

Pop-up menus. The menus are designed to help authors select from predefined by the teacher or by the system values or defaults such as: categories of activities, characterizations of answers, teaching strategies.

The knowledge base. This data base includes the educational material of text, questions, and dialogues.

Association buttons. They are buttons designed to help authors establish causal relationships between text elements such as text-unities and make associations such as between educational material and learners' profiles, teaching strategies and learners' profiles, learners' profiles and dialogue plans.

Guidance tips. They are information tips designed to support the author by giving back the appropriate feedback to his actions that is confirmation or not of the completion of each step.

Administrative tools. These tools are for managing the lists of users, the roles of the users (teachers or students), the categories of activities, the activities, reports on carried out activities (log files for each student).

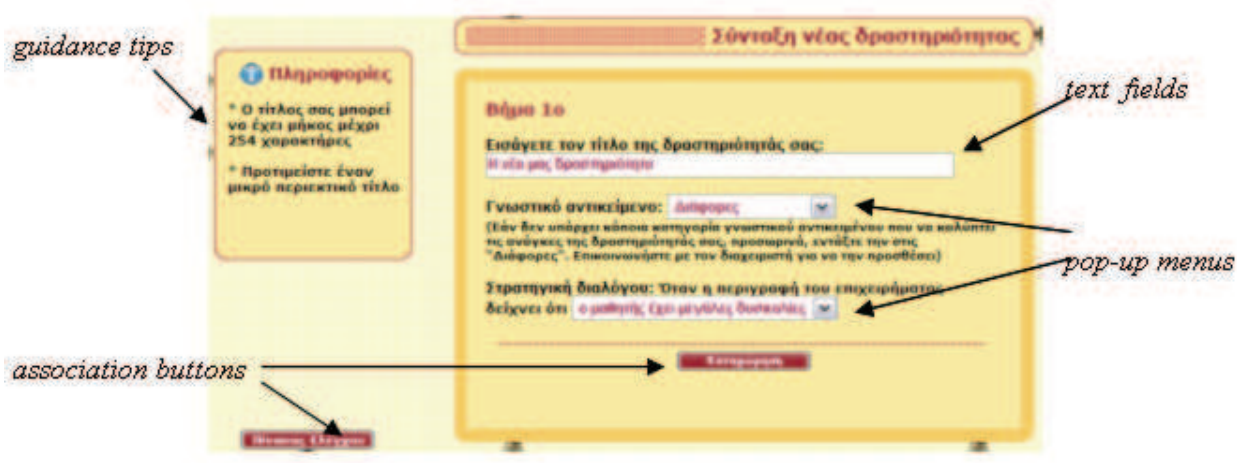

Figure 1. The ReTuDiSAuth: Tools for structuring and elaborating a dialogue activity

The shell delivers the educational material according to the instructions generated by the author using the tools in combination with its predetermined defaults. A semantic network is created by the author using the association buttons. The nodes of the network represent the elements of the material and the branches represent possible paths followed by the learner while participating in instructional activities. While delivering the educational material to a learner in a specified manner the shell constructs his learner model. The values of the learner model change over the activity course as the learner participates in dialogues. 


\section{Text Structuring with RETUDISAuth}

School and university text-books usually include texts not structured according to any theory of text comprehension. Authors of such texts usually ignore micro and macro structure. Research held with participation of 60 students studying Didactics of Informatics in the Department of Informatics and Telecommunications, University of Athens during the academic year 2006-2007, asked students to select texts and write questions for text comprehension (Tsaganou \& Grigoriadou, 2008). The research results indicated that selected texts embody mainly descriptions of micro structure, whereas descriptions of macro structure were very poor or fragmentary. On the other hand, questions reported by the students included descriptions of macro structure.

Structuring a text is a demanding process. The text should be organized and structured in order to include descriptions on micro and macro-level representation of the knowledge domain. Since this is difficult, authors can lie heavy on the construction of the appropriate questions about the text. ReTuDiSAuth involves the author in the following processes concerning text, questions and dialogue structure (Tsaganou et al., 2004; Grigoriadou \& Tsaganou, 2007).

\section{Text structure}

The author selects the text from a text-book and identifies the cognitive categories. He separates the text in sections, each of which represents a cognitive category and gives a phrase as a title for every section. Titles help in organizing the structure of the questions and dialogues activities. The author specifies the cognitive categories involved and the number of them. For example, in case of technical text are used four cognitive categories: entity, state, event and action. In case of historical text have been used three cognitive categories: state, event and action (Tsaganou et al, 2004; Grigoriadou et al., 2005; Grigoriadou \& Kanidis, 2003).

\section{Questions with alternative answers}

For every section the author submits simple questions or question-pairs to the system and the related alternative answers. The first question in a question-pair is related to the section and the learner's alternative answer concerning this question is declared to the system as position. The second question is related to the learner's justification concerning a position and is declared to the system as justification. Position and justification represent the causal relationships in the text. Each question or question-pair refers to a description on microlevel of the relational system: (a) description of units that constitute the system, (b) description of part to whole relations connecting system units and (c) description of static states of the units. Or to a description of the transformational system: (a) description of events and events' sequence taking place in these units, (b) description of causal and temporal relationships between events and the changes bringing on the static states. The teleological system includes description of the system on macro-level throughout a "tree" of predefined goals and sub-goals for every transformation of the system from one state to another. 


\section{Local Network Operation}

A computer network is often classified as being either a local area network (LAN), a metropolitan area network (MAN) or a wide area network (WAN). Another means of classifying networks is based on the topology of the network, which refers to the pattern in which the machines are connected. Three popular topologies are: (1) bus, in which the machines are connected to a common communication line called a bus, (2) ring, in which the machines are connected in circular fashion and (3) star, in which one machine serves as a central focal point to which all the others are connected.

A bus topology is designed with each node connected directly to a high-data speed bus. Nodes communicate across the network by passing packets of data through the bus (they read and write data -in the form of packets). Packets placed on the bus, transfer messages to nodes. A message includes the receiver's address, which specifies the network address of the target node. A node watches the bus continuously and reads the target address of each packet. After that, the node compares the address with its own, and if they are the same, then reads the message of the packet, otherwise ignores it. When a node is ready to broadcast a message, waits until the bus is free and then begins passing it to the bus. If a node uses the bus it watches it and can be aware of any other node using the bus at the same time. In that case both nodes stop using the bus waiting until one of them accidentally attempts to us it. When a limited number of packets are simultaneously transmitted throughout the bus, them this competence strategy is successful. The bus topology network can work even in case of disconnection of a node (Brookshear, 2005) .....

Question 1 (Identification of local network units).

1) In a local network which of the following is a node.

- A server

- A packet

- A bus

Question 2 (Identification of events and events' sequence).

2a) In a bus topology network, what happens in case there is an interruption (a cut off) of the bus. Select one of the following answers.

- the network crashes (non scientific)

- the network continuous to work properly (towards scientific)

- the network is divided into two independent networks each one working properly (scientific)

2b) Justify your answer by selecting one of the following answers.

- because all nodes are connected with the bus and they cannot communicate if there is a cut off (non scientific)

- $\quad$ because all nodes have spare connections between each other that can operate without the bus (towards scientific)

- because a bus network needs only a central bus to connect the nodes to (scientific)

Figure 2. Text fragment and questions with alternative answers given by a student 
In Figure 2, Question 1 is related to description of units that constitute the local network system (relational system). Question 2 is related to description of events taking place in the system, relationships between events and the changes bringing from one state to another (transformational system).

\section{Dialogue structure}

Defining argument completeness. For every question-pair the combination of the learner's position and the corresponding justification constitutes the learner's argument. Arguments are classified as complete, when both position and justification are scientific. Otherwise the argument is non-complete. The author defines the different degrees of argument completeness. Possible values of argument completeness are: complete, almost complete, intermediate, nearly incomplete and incomplete.

Forming dialogues. The author creates a library consisting of specific dialogue-parts for all combinations of possible answers and associates them with the corresponding answers. Each specific dialogue-part is designed to remedy a particular learning difficulty. The specific dialogue-parts are dependent on the specific text. The specific dialogue-parts of different types are associated with predefined and embedded in the system dialogue tactics Forming dialogue tactics. Dialogue tactics, inspired by the general teaching strategies (Collins, 1987; Graesser, 2001), are hints or Socratic-style dialogues. Tactics correspond to different levels of dialogue concerning the specific subject matter and involve learners in activities which promote reflection. The author defines the dialogue tactics which have the following forms: (a) picks positive or negative examples, (b) picks counterexamples, (c) generates hypothesis, (d) makes learner to form hypothesis, (e) makes learner to test hypothesis, (f) entraps the learner, ( $\mathrm{g}$ ) traces consequences to a contradiction or faulty knowledge of a learner and $(\mathrm{h})$ promotes questioning authority.

Selecting dialogue strategy. The choice of the dialogue strategy is decided in the beginning. Example of a strategy embedded in the system is the following (Grigoriadou et al., 2005): "The system sorts learners' argument classifications in a list according to decreasing degree of argument completeness. The tutorial dialogue begins with a discussion about the unity for which the learner seems to face less learning difficulties. The system generates the sequence of dialogue-parts for this unity. Then the system prepares the next dialogue-part, based on the results of the previous dialogue-part".

Selecting dialogue tactics. Predefined dialogue tactics are accessed throughout a pop-up menu. The author selects a predefined dialogue tactic and formulates the dialogue-part.

Planning dialogue. For the selected teaching strategy and depending on the learner profile the system constructs the initial dialogue plan for the learner. The system uses: (a) the general dialogue-parts, which include typical dialogue-parts, concerning participation of the learner in dialogue, encouragement, motivation, agreement or not with the system, guidance etc. and (b) the specific dialogue-parts that were previously entered by the author according to the appropriate dialogue goals and tactics. During entering the author has made the appropriate associations between contradicting answers (contradictions between learner's position and his justification concerning causal relationships in the text) and dialogue-parts for all possible combination of answers. So as, the system becomes able to initiate the dialogue and generate dynamically the appropriate dialogue in response to the learners' feedback during the dialogue process. 
Defining learners' profiles. Learners can be described as belonging to one of a set of authordefined learner profiles taking into account the number of learner's arguments with high degree of argument completeness.

\section{Evaluation}

Formative evaluation, concerning the use of ReTuDiSAuth for text structuring, was conducted with the participation of 26 postgraduate students and 6 experts in informatics domain at the University of Athens. Evaluation aimed at further revisions, modifications and improvements of ReTuDiSAuth as well as of ReTuDiS system (Muray, 2003). The participants were given explanations about the aims of the authoring tool.

Students were asked to participate in the evaluation process and perform representative tasks: (a) to prepare source material text and questions with alternative answers of their choice and (b) to use the system for the construction of dialogue activities. Each student proposed a two pages text, three question- pairs with alternative answers involving causal relationships and specific dialogues-parts.

Experts used the material proposed by the students in order to identify and comment issues concerning specific problems or deficiencies users face in formulating learning goals, questions and tutoring dialogues and the educational benefits of the process.

Both students and experts were given a questionnaire and commented about usability, learnability and efficiency:

- the depth to which the system can infer a learner's knowledge, respond accordingly and teach

- if the system can support dialogue activities on different knowledge domains

- how easy non-programmers can learn to use the system

- how quickly a trained user can construct questions and dialogue activities

- the amount of resources needed to construct questions and dialogue activities

Moreover, experts were asked to comment about:

- $\quad$ how much the underlying instructional model of the system constrains the author

- the sources of teaching and domain expertise

- the level of expertise / background of the target authors.

In general, most of the experts faced minor difficulties in using the interface. Experts spent more time to overcome difficulties in structuring the text and matching text paragraphs with cognitive categories. Experts commended about the quantity and the quality of questions made by the students. They identified as beneficial the method used for training students, which may be potential teachers, for the improvement of their authoring skills for textbased dialogue activities.

\section{Conclusions}

Research results of the effectiveness of ReTuDiSAuth environment as an authoring tool for structuring educational text material were presented. Students experimented in the environment and designed text, questions and dialogue activities that promote learners' reflection. Evaluation got hold of representative users: graduate students and experts.

We explored the role of the learner in authoring environment. Analysis of the current study indicated that authoring makes students improve their authoring skills and become familiar 
with text structuring and question constructing. Educational benefit of this process was the way the environment easily allowed students to add educational material by taking advantage of the system's interactive features. Experts found the system appropriate for the education of postgraduate students as teacher and authors, by offering them considerable power to construct appropriate domain material, create effective learning environments and test their own teaching strategies.

Currently, we are exploring improvement of the system concerning direct specification of causal connections between text elements during text structuring. Moreover, as ReTuDiS does offer significant advantages for classroom use and generate important learning outcomes, we plan further research into the evaluation of the system in complex classroom conditions and compare results in different knowledge domains.

\section{References}

Ainsworth, S., Major, N., Grimshaw, S., Hays, M., Underwood, J, Williams, B. et al. R. (2003). REDEEM: Simple Intelligent Tutoring Systems from Usable Tools. In: Authoring Tools for Advanced Technology Learning Environments, Murray, T., Blessing, S., Ainsworth, S. (Eds.), 205-232, Kluwer Academic Publishers, ISBN:1402017723, The Netherlands.

Arruarte, A., Ferrero, B., Fernandez-Castro, I., Urretavizcya, M., Alvarez, A., \& Greer, J. (2003). The IRIS Authoring Tool. In: Authoring Tools for Advanced Technology Learning Environments, Murray, T., Blessing, S., Ainsworth, S. (Eds.), 233-267, Kluwer Academic Publishers, ISBN:1402017723, The Netherlands .

Blessing, S., (2003). A Programming by Demonstration Authoring Tool for Model-Tracing tutors. In: Authoring Tools for Advanced Technology Learning Environments, Murray, T., Blessing, S., Ainsworth, S. (Eds.), 93-119, Kluwer Academic Publishers, ISBN:1402017723, The Netherlands.

Baudet, S., \& Denhière, G. (1992). Lecture Comprehension de Texte et Science Cognitive, Presses Universitaires de France, Paris.

Brookshear J G. (2005). Computer Science: An Overview, Pearson International Edition, 9th Edition.

Brown, A.L., \& Day, J.D. (1983). Macrorules for summarizing texts: The development of expertise. Journal of Verbal Learning and Verbal Behavior, 22 1-14.

Collins, Al. (1987). A Sample Dialogue Based on a Theory of Inquiry Teaching. In: Instructional Theories in Action, Reigeluth, Ch. (Ed.), 181-199, Lawrence Erlbaum Associates Inc., Hillsdale.

DeCorte, E. Verschaffel, L. \& DeWin, L. (1982). Influence of rewording verbal problems on children's problem representations and solutions. Journal of Educational Psychology, 77, 460-470.

Graesser, A. (2001). Teaching Tactics and Dialog in Auto-Tutor, International Journal of Artificial Intelligence in Education, 12 257-279.

Graesser, A. \& Tipping, P. (1999). Understanding Texts. In: A Companion to Cognitive Science, Bechtel, W. \& Graham, G. (Eds.), Blackwell, Malden MA. 
Grigoriadou, M., \& Kanidis, V. (2003). Cognitive Aspects in Teaching the Computer Cache Memory with Learning Activities based on a Coherent Technical Text and a Simulation Program. Proceedings of the 6th Hellenic European Conference on Computer Mathematics \& its Applications (HERCMA03) - Minisymposium: Informatics in Cognitive Sciences, 429-235, LEA Publishers, Athens, Greece .

Grigoriadou, M., Tsaganou, G., \& Cavoura, Th. (2005). Historical Text Comprehension Reflective Tutorial Dialogue System, Educational Technology \& Society Journal, Special issue, 8(40), 31-40.

Grigoriadou, M., Tsaganou, G., (2007). Authoring Tools for Structuring Text Based Activities, Proceedings of the 4th International Conference on Universal Access in Human-Computer Interaction (UAHCI 2007), Volume 7, 319-328, LNCS_4556, ISBN: 978-3-540-73282-2, Beijing, P.R. China.

Jonassen, D., (2004). Model Building for Conceptual Change: Using Computers as Cognitive Tools. Proceedings of the 4rd Panellenic Conference with International Participation: Information and Communication Technologies in Education (ETPE2004), Grigoriadou, M., Raptis, A., Vosniadou, S. \& Kynigos, X. (Eds.), 4-17, Athens, Greece.

Leon, J., Penalba, G. (2002). Understanding Causality and Temporal Sequence in Scientific Discourse. In: The Psychology of Science Text Comprehension, Otero, J., Leon, J., Graesser, A. (Eds.), Lawrence Earlbaum Associates, Publishers, London.

Kay, J. (2001). Learner control. User Modeling and User-Adapted Interaction, 11, 11-127.

Kintsch, W. (1998). Compréhension: a paradigm for cognition, Cambridge University Press, UK.

Koedinger, K. \& Anderson, J. (1995). Intelligent Tutoring Goes to the Big City. International Journal of Artificial Inteligence in Education, 8, 30-43.

McNamara, D.S., Kintsch, E., Songer, N.B., \& Kintsch, W. (1996). Are good texts always better? Text coherence, background knowledge, and levels of understanding in learning from text. Cognition and Instruction, 14, 1-43

Morgan, M.S. (1999). Learning from Models. In: Models as mediators: Perspectives on natural and social science, M.S. Morgan \& M. Morrison (Eds.), 347-388, Cambridge: Cambridge University Press.

Muray, T. (2003). An Overview of Intelligent Tutoring System Authoring Tools: Updated analysis of the state of the art. In: Authoring Tools for Advanced Technology Learning Environments, Murray, T., Blessing, S., Ainsworth, S. (Eds.), 491-544, Kluwer Academic Publishers, ISBN:1402017723, The Netherlands,.

Ritter, S., \& Blessing, S. (1998). Authoring tools for Component-Based Learning Environments. Journal of the Learning Science, 7(1), 107-132.

Schultz, K., Bratt, E. O., Clark, B., Peters, S., Ponbarry, H. \& Treeratpituk, P. (2003). A Scalable, Reusable, Conversational Tutor: SCoT. Proceedings of the 11th International Conference on Artificial Intelligence in Education Workshop: Tutorial Dialogue Systems, 367-377, Sydney, Australia.

Tsaganou, G., Grigoriadou, M., Cavoura, Th., Koutra, D., (2003). Evaluating an Intelligent Diagnosis System of Historical Text Comprehension. Expert Systems with Applications, 25(4), 493-502, ISSN: 0957-4174. 
Tsaganou, G., Grigoriadou, M. \& Cavoura, Th. (2004). W-ReTuDiS: a Reflective Tutorial Dialogue System. Proceedings of the 4rd Panellenic Conference with International Participation: Information and Communication Technologies in Education, Grigoriadou, M., Raptis, A., Vosniadou, S. \& Kynigos, X. (Eds.), 738-746, Athens, Greece.

Tsaganou, G., Grigoriadou, M., (2008). «Text and Dialogue Structure Analysis Matching a Theory of Text Comprehension». Proceeding of 4th Hellenic Conference "Didactics of informatics", Komis B. (eds.), 333-342, Patra, Greece, ISBN 978-960-6759-07-9.

Van Dijk, T.A., \& Kintsch, W. (1983). Strategies of discourse comprehension. Academic Press, ISBN-10: 0127120505, New York.

Wong, W. K. \& Chan, T. W. (1997). A Multimedia Authoring System for Crafting Topic Hierarchy, Learning Strategies and Intelligent Models. International Journal of Artificial Intelligence in Education, 8(1), 71-96, ISSN 1560-4292. 


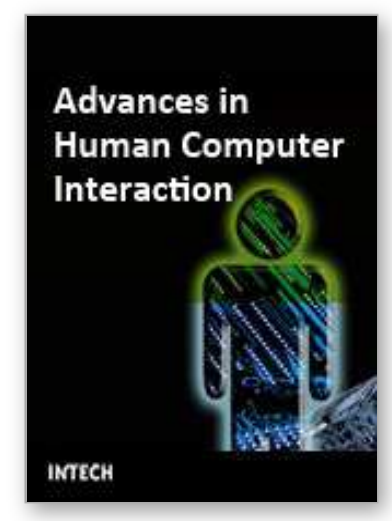

\section{Advances in Human Computer Interaction \\ Edited by Shane Pinder}

ISBN 978-953-7619-15-2

Hard cover, 600 pages

Publisher InTech

Published online 01, October, 2008

Published in print edition October, 2008

In these 34 chapters, we survey the broad disciplines that loosely inhabit the study and practice of humancomputer interaction. Our authors are passionate advocates of innovative applications, novel approaches, and modern advances in this exciting and developing field. It is our wish that the reader consider not only what our authors have written and the experimentation they have described, but also the examples they have set.

\section{How to reference}

In order to correctly reference this scholarly work, feel free to copy and paste the following:

Grammatiki Tsaganou and Maria Grigoriadou (2008). Design of Text Comprehension Activities with RETUDISAuth, Advances in Human Computer Interaction, Shane Pinder (Ed.), ISBN: 978-953-7619-15-2, InTech, Available from:

http://www.intechopen.com/books/advances_in_human_computer_interaction/design_of_text_comprehension _activities_with_retudisauth

\section{INTECH}

open science | open minds

\section{InTech Europe}

University Campus STeP Ri

Slavka Krautzeka 83/A

51000 Rijeka, Croatia

Phone: +385 (51) 770447

Fax: +385 (51) 686166

www.intechopen.com

\section{InTech China}

Unit 405, Office Block, Hotel Equatorial Shanghai

No.65, Yan An Road (West), Shanghai, 200040, China

中国上海市延安西路65号上海国际贵都大饭店办公楼 405 单元

Phone: +86-21-62489820

Fax: $+86-21-62489821$ 
(C) 2008 The Author(s). Licensee IntechOpen. This chapter is distributed under the terms of the Creative Commons Attribution-NonCommercialShareAlike-3.0 License, which permits use, distribution and reproduction for non-commercial purposes, provided the original is properly cited and derivative works building on this content are distributed under the same license. 